\title{
RANCANG BANGUN ANTENA YAGI 2.4 GHZ UNTUK MEMPERKUAT SINYAL WIFI (WIRELESS FIDELITY)
}

\author{
Rapha Nichita Kaikatui ${ }^{1}$, Roberto Corputty ${ }^{2}$ \\ 1,2Jurusan Teknik Sipil, Fakultas Teknik, Universitas Musamus Merauke. \\ Email: ${ }^{1}$ naiirapha26@gmail.com, ${ }^{2}$ roberto@unmus.ac.id
}

\begin{abstract}
ABSTRAK
Wireless Local Area Network (WLAN) adalah suatu jaringan area lokal tanpa kabel yang menggunakan frekuensi radio sebagai media transmisinya. Namun, keterbatasan jarak merupakan sebuah masalah yang dihadapi oleh perangkat WLAN ini. Jarak jangkauan sinyalnya yang terbatas sehingga memerlukan suatu solusi untuk memperluas jarak jangkauan sinyal tersebut. Pemanfaatan antena yagi sebagai penguat merupakan solusi dalam menjawab masalah keterbatasan jarak jangkauan WLAN.

Proses perancangan, perhitungan dan perakitan antena, untuk panjang setiap elemen antena director $5.62 \mathrm{~cm}$, reflector $6.535 \mathrm{~cm}$ dan driven yang dipisahkan masing-masing 2.968 $\mathrm{cm}$. Pengujian dilakukan pada kondisi cuaca cerah dan kondisi cuaca hujan serta untuk kondisi LOS dan Non LOS, dengan lokasi penelitian Gang Kasmin Jalan Raya Mandala Kabupaten Merauke.

Antena Yagi sebagai penguat yang beroperasi pada frekuensi kerja WLAN yaitu 2400 $\mathrm{MHz}$ sebagai penguat dapat meningkatkan sinyal wifi dengan perolehan gain sebesar $3 \mathrm{~dB}$.
\end{abstract}

Kata Kunci : Antena, Sinyal, Penguat, WLAN, Penguat Sinyal 


\section{PENDAHULUAN}

\section{A. Latar Belakang}

Komunikasi memiliki peranan penting, dengan telekomunikasi orang saling bertukar informasi satu dengan yang lainnya. Perkembangan teknologi yang semakin pesat membuat manusia ingin saling berkomunikasi tanpa adanya keterbatasan jarak, waktu dan ruang. Kehadiran kabel dalam pengkoneksian antar komunikasi dinilai merepotkan. Konsep yang digunakan untuk mengganti kabel adalah dengan menggunakan frekuensi radio. Wireless LAN (WLAN) menjadi salah satu pilihan yang terbaik.

Antena merupakan elemen penting dalam komunikasi nirkabel. Bisa diartikan antena sebagai jembatan komunikasi antara satu perangkat komunikasi dengan yang lainnya, karena perkembangan itu maka muncul wireless local area network (WLAN) menggunakan frekuensi radio dan udara bebas sebagai transmisinya sehingga sangat efesien. Antena Yagi yang dulunya hanya digunakan sebagai antena penerima siaran televisi dan penerima radio amatir, kini dapat digunakan sebagai perangkat penerima WLAN. Antena Yagi merupakan salah satu antena directional yang cocok digunakan sebagai penerima WLAN yang dapat mengambil dan menerima sinyal pada satu arah. Antena Yagi menggunakan elemen pasif sehingga menghasilkan penguatan gain sinyal yang baik.

Wifi merupakan inovasi dalam teknologi komunikasi dan informasi yang bekerja pada jaringan dan perangkat Wireless Local Area Network (WLAN). Wifi menggunakan frekuensi radio sebagai sarana transmisinya, yang bekerja pada peralatan portable untuk mengakses jaringan. Wifi terhubung pada kabel LAN dan memperluas jaringan keperalatan mobile computing. Pada saat ini wifi telah diimplementasikan dalam berbagai bidang, dan salah satunya adalah untuk memberikan layanan internet bagi masyarakat. Teknologi wifi memungkinkan para penggunanya untuk mengakses internet secara nirkabel namun dengan range yang terbatas. Frekuensi 2,4 GHz sudah banyak digunakan diseluruh dunia, karena merupakan standar dari IEEE 802.11 untuk wireless LAN. Teknologi wifi memungkinkan para penggunanya untuk mengakses internet secara nirkabel namun dengan range yang terbatas yaitu hanya sejauh \pm 100 meter dari titik akses (hotspot). Namun pada kenyataannya belum mencapai 100 meter sudah terjadi kehilangan sinyal wifi.

\section{B. Rumusan Masalah}

Latar belakang masalah diatas, dapat dirumuskan permasalahannya adalah:

"Bagaimana merancang bangun sebuah antena yagi yang dapat bekerja pada 
frekuensi 2,4 GHz untuk aplikasi WLAN sebagai penguat sinyal wifi”.

\section{METODE PENELITIAN}

Metode penelitian dibagi dalam beberapa tahapan :

1. Perancangan

2. Pengukuran.

3. Perakitan.

4. Pemasangan

5. Pengujian

6. Pengelolaan Data

7. Kesimpulan

Keseluruhan Proses penelitian ini merupakan satu kesatuan yang dilakukan secara bertahap dengan lokasi yang berbeda diamana, proses perancangan pengukuran dan perakitan dilakukan di LAB Jurusan Teknik Elektro. Proses Pemasangan, Pengujian, pengelolaan data serta kesimpulan dilakukan pada lokasi penelitian.

\section{LANDASAN TEORI}

\section{A. Pengertian Antena Yagi-Uda RF}

Antena Yagi adalah salah satu jenis antena radio atau televisi yang diciptakan oleh Hidetsugu Yagi. Antena ini bersifat direksional, yaitu menambah gain hanya pada salah satu arahnya. Sisi antena yang berada di belakang reflektor memiliki gain yang lebih kecil daripada di depan direktor. Antena Yagi atau antena Yagi-Uda RF digunakan secara luas dan merupakan salah satu antena desain paling sukses atau banyak digunakan untuk aplikasi RF direktif. Antena Yagi-Uda adalah nama lengkapnya, pada umumnya dikenal dengan sebutan Yagi atau antena Yagi. RF singkatan dari Radio frequency atau frekuensi radio.

\section{B. Prinsip Antena Yagi-Uda RF}

Antena Yagi-Uda RF digunakan untuk menerima dan mengirim pada satu arah sehingga memiliki gain yang bagus sekitar 3 - $20 \mathrm{dBd}$, dan antena Yagi bekerja pada jangkauan frekuensi $30 \mathrm{MHz}$ sampai $3 \mathrm{GHz}$ dengan jarak 40 sampai $60 \mathrm{~km}$, itu artinya antena ini berbeda dengan antena dipole standar. Bagian-bagian dari antena Yagi dilihat pada gambar 1 .

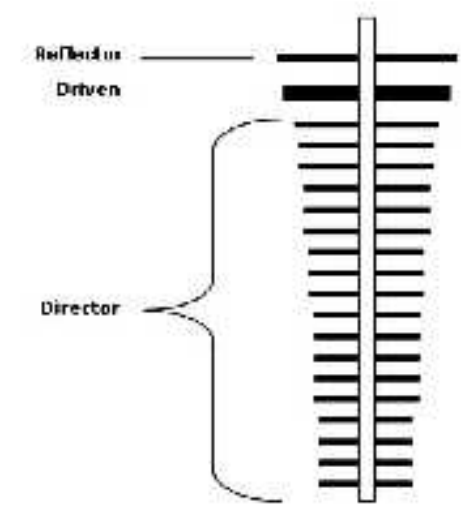

Gambar 1. Bagian-bagian antena YagiUda RF.

C. Elemen Penyusun Antena Yagi-Uda RF Antena Yagi-Uda RF disusun dengan beberapa elemen yang terdiri dari :

1. Reflector

Reflector berada dibelakang dipole dan lebih panjang 5-9 \% dari dipole, reflector disini berfungsi sebagai memantulkan 
sinyal yang terlewat dari elemen tengah dan dikembalikan.

2. Director

Director sendri biasanya lebih pendek 5$9 \%$ dari dipole dan berfungsi untuk mengarahkan sinyal ke arah yang ditujukan.

3. Driven

Driven Element adalah suatu elemen yang menyediakan daya dari pemancar, biasanya melalui saluran transmisi. Panjang fisik driven adalah setengah panjang gelombang $(0,5 \quad \lambda)$ dari frekuensi radio yang dipancarkan atau diterima.

4. Crossbar atau boom

Crossbar atau boom sebagai bagian antena yang memegang tiap elemen tersebut. Perlu mengarahkan crossbar atau boom antena pada arah datangnya sinyal untuk menerima sinyal dengan maksimal.

\section{Jarak Antar Elemen}

Jarak antar elemen sangat mempengaruhi pengkopelan bersama (mutual coupling) antara elemen yang satu dengan elemen yang lain. Untuk saat sekarang ini belum ada formula khusus untuk merancang antena Yagi terbaik untuk band manapun. Tetapi dari hasil percobaan para ahli antena amatir didapatkan data - data yang menunjang untuk merancang antena Yagi.
Menurut G.H. Brown gain terbesar dari sebuah elemen parasit tunggal didapatkan dari penempatan jarak antara elemen dari 2 buah elemen.

Pada operasi reflektor, reflektor bekerja pada frekuensi yang lebih rendah dari pada frekuensi feed point atau driven element (dengan cara memanjangkan sedikit lebih panjang daripada panjang driven element) dan agar memperoleh gain maksimum, jarak antara elemen dijaga agar tidak melebihi $0.25 \lambda$. Syarat jarak antara reflektor dengan driven element yang diizinkan adalah $0.15 \lambda$ sampai $0.25 \lambda$.

Direktor atau pengarah dikonfigurasi pada frekuensi tinggi (dengan memendekkan elemen sedikit lebih pendek daripada driven element) dan untuk memperoleh gain maksimum, jarak antara driven element dengan director diusahakan melebihi $0.1 \lambda$ dan tidak melebihi $0.15 \lambda$. Jadi syarat jarak antara driven element dan director yang diizinkan adalah $0.1 \quad \lambda$ sampai $0.15 \lambda$ (Firmanto, 2010).

\section{E. Parameter pada perancangan antena}

Parameter yang dibutuhkan pada perancangan sebuah antena Yagi-Uda RF penguat signal adalah :

1. Panjang gelombang diudara $(\lambda)$

$$
\lambda=\frac{c}{f}
$$

Dimana:

$$
\mathrm{c}=\text { Kecepatan cahaya }
$$


$\mathrm{f}=$ Frekuensi yang digunakan

2. Panjang driven

$$
\mathrm{L}=\mathrm{K} \times \lambda
$$

Dimana:

$$
\begin{aligned}
\mathrm{L} & =\text { Panjang driven } \\
\mathrm{K} & =\text { Velocity factor (pada logam) } \\
& =0.95 \\
\lambda & =\text { Panjang gelombang }
\end{aligned}
$$

3. Panjang reflector lebih panjang $7 \%$

$$
\mathrm{Lr}=(\mathrm{L} \times 7 \%)+\mathrm{L}
$$

4. Panjang director lebih pendek 5\%

$$
\mathrm{Ld}=(\mathrm{L} \times 5 \%)-\mathrm{L}
$$

\section{F. WIFI (Wireless Fidelity)}

Wireless adalah koneksi suatu perangkat dengan perangkat lainnya tanpa menggunakan kabel. Wireless internet merupakan koneksi internet yang menggunakan frekuensi radio dan bekerja pada kecepatan tinggi yaitu 11-54 Mbps, jauh lebih cepat daripada layanan internet melalui telepon yang hanya kecepatan maksimum 56 Kbps (milik telkom). Pemakaian wireless internet memungkinkan akses internet selama 24 jam dengan biaya sangat murah karena wireless internet tidak akan dikenakan pulsa, sehingga pemakai hanya dikenakan biaya pembayaran kepada Internet Service Provider (ISP) (Iqbal, M 2012).

Wifi kependekan dari Wireless fidelity, adalah sekumpulan standar yang digunakan untuk jaringan lokal nirkabel (Wireless Local Area Network -WLAN).
Secara teknis operasional, wifi merupakan salah satu varian teknologi komunikasi dan informasi yang bekerja pada jaringan dan perangkat WLAN (Wireless Local Area Network). Dengan kata lain, wifi adalah nama dagang (certification) yang diberikan pabrikan kepada perangkat telekomunikasi (internet) yang bekerja di jaringan WLAN dan sudah memenuhi kualitas interoperability yang dipersyaratkan.

\section{PERANCANGAN ANTENA}

\section{A. Perancangan}

Perancangan Antena dilakukan sesuai dengan frekuensi antenna yaitu $24 \mathrm{GHz}$ serta disesuaikan dengan frekuensi kerja dari radio link yang digunakan sebagai sumber sinyal wifinya.

Model rancangan antena yagi penguat wifi dapat dilihat pada gambar 2 .

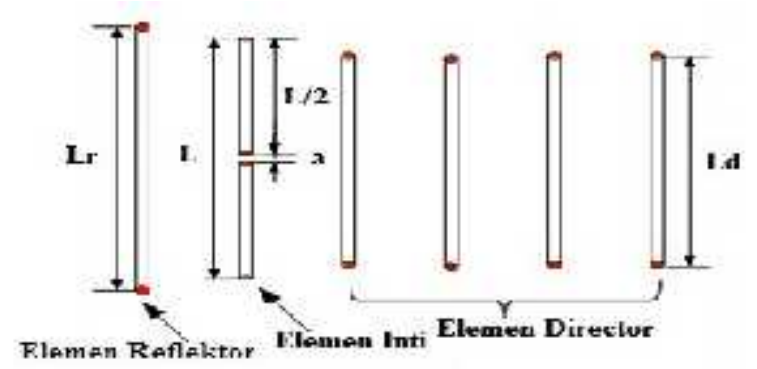

Gambar 2. Model Antena Yagi

Keterangan :

$\lambda$

: panjang gelombang diudara

$$
=12.5 \mathrm{~cm}
$$

L : panjang elemen driven

$$
=5.937 \mathrm{~cm}
$$

L/2 : panjang driven yang harus 
dipisah $=2.968 \mathrm{~cm}$

a $\quad$ jarak antara elemen driven $=$ $0.125 \mathrm{~cm}$

Lr : panjang elemen Reflektor $=$ $6.353 \mathrm{~cm}$

Ld : Panjang elemen Director = $5.640 \mathrm{~cm}$

\section{B. Parameter Perhitungan Antenna Yagi Penguat Sinyal Wifi}

Setelah mengumpulkan teori dan komponen yang dibutuhkan, dilakukan perhitungan untuk merancang antenna yagi penguat sinyal wifi agar dapat bekerja dengan baik sebagai penguat. Antena yang dirancang pada penelitian adalah antena Yagi yang memiliki frekuensi kerja $2.4 \mathrm{GHz}$. Parameter rumus yang digunakan berdasarkan persamaan yang ada dalam bab II adalah sebagai berikut:

1. 1. Panjang Gelombang

$$
\begin{array}{ll}
\lambda & =\frac{\mathrm{c}}{f} \\
\lambda & =\frac{3.10^{8}}{24.10^{8}} \\
\lambda & =12.5 \mathrm{~cm}
\end{array}
$$

Berdasarkan panjang gelombang driven elemen.

maka perhitungan setiap elemen dapat4. Panjang Reflektor dihitung, karena panjang gelombang (lamda) sebagai parameter perhitungan setiap elemen antenna yagi penguat sinyal wifi.

2. Panjang elemen driven yang dibuat

$\mathrm{L}=0.5 \times \lambda \times \mathrm{K}$

$$
\begin{aligned}
& =0.5 \times 12.5 \times 0.95 \\
& =5.9375 \mathrm{~cm}
\end{aligned}
$$

Elemen driven yang harus dipisahkan

$$
\begin{gathered}
=\frac{5.9375}{2} \\
=2.96875 \mathrm{~cm}
\end{gathered}
$$

3. Jarak antara elemen driven yang dipisahkan

$$
\begin{aligned}
& \mathrm{a} \quad=0.01 \times \lambda \\
& \text { a } \quad=0.01 \times 12.5 \\
& =0.125 \mathrm{~cm} \\
& =1.25 \mathrm{~mm}
\end{aligned}
$$

Berdasarkan perhitungan rumus driven yaitu panjang driven yang dipisahkan, dan jaraknya maka didapat elemen inti siap dirakit, selanjutnya menghitung elemen reflector, director, dan jarak setiap elemenelemen.

Antena Yagi umumnya terdiri atas 3 buah elemen utama yaitu sebuah driven element, sebuah reflektor, dan sebuah direktor. Seperti yang sudah dijelaskan pada bab sebelumnya, reflektor diatur lebih panjang sedikit dari driven elemen sedangkan direktor diatur sedikit lebih pendek daripada $\mathrm{Lr}$

$$
\begin{aligned}
& =(\mathrm{L} \times 7 \%)+\mathrm{L} \\
& =(5.9375 \times 7 \%)+5.9375 \\
& =6.353 \mathrm{~cm}
\end{aligned}
$$

5. Panjang Director

Ld

$$
=(\mathrm{L} \times 5 \%)-\mathrm{L}
$$




$$
\begin{aligned}
& =(5.9375 \times 5 \%)-5.9375 \\
& =5.640 \mathrm{~cm}
\end{aligned}
$$

Perancangan antenna yagi penguat sinyal wifi dirakit dengan 15 elemen. Penambahan batang director akan menambah gain antena, namun akan membuat pola pengarahan antena menjadi lebih sempit. Semakin banyak jumlah director, maka semakin sempit arah pancarannya.

Panjang elemen antenna yagi yang dirancang dapat dilihat dalam Tabel 1 dibawah ini :

Tabel 1. Ukuran Panjang Elemen Antena Yagi

\begin{tabular}{|c|c|c|c|}
\hline $\begin{array}{c}\text { Jenis } \\
\text { Elemen }\end{array}$ & $\begin{array}{c}\text { Panjang } \\
\text { (cm) }\end{array}$ & $\begin{array}{c}\text { Jenis } \\
\text { Elemen }\end{array}$ & $\begin{array}{c}\text { Panjang } \\
\text { (cm) }\end{array}$ \\
\hline $\begin{array}{c}\text { Reflektor } \\
\text { (R) }\end{array}$ & 6.353 & $\begin{array}{c}\text { Direktor 7 } \\
\text { (D7) }\end{array}$ & 4.82 \\
\hline $\begin{array}{c}\text { Drivent } \\
\text { Elemen } \\
\text { (DE) }\end{array}$ & 5.937 & $\begin{array}{c}\text { Direktor 8 } \\
\text { (D8) }\end{array}$ & 4.62 \\
\hline $\begin{array}{c}\text { Direktor 1 } \\
\text { (D1) }\end{array}$ & 5.62 & $\begin{array}{c}\text { Direktor 9 } \\
\text { (D9) }\end{array}$ & 4.44 \\
\hline $\begin{array}{c}\text { Direktor 2 } \\
\text { (D2) }\end{array}$ & 5.42 & $\begin{array}{c}\text { Direktor } \\
\text { 10 (D1) }\end{array}$ & 4.21 \\
\hline $\begin{array}{c}\text { Direktor 3 } \\
\text { (D3) }\end{array}$ & 5.33 & $\begin{array}{c}\text { Direktor } \\
\text { 11 (D1) }\end{array}$ & 4.02 \\
\hline $\begin{array}{c}\text { Direktor 4 } \\
\text { (D4) }\end{array}$ & 5.20 & $\begin{array}{c}\text { Direktor } \\
12 \text { (D1) }\end{array}$ & 3.91 \\
\hline $\begin{array}{c}\text { Direktor 5 } \\
\text { (D5) }\end{array}$ & 5.11 & $\begin{array}{c}\text { Direktor } \\
\text { 13 (D1) }\end{array}$ & 3.83 \\
\hline $\begin{array}{c}\text { Direktor 6 } \\
\text { (D6) }\end{array}$ & 4.91 & $\begin{array}{c}\text { Direktor } \\
\text { 14 (D1) }\end{array}$ & 3.70 \\
\hline & $\begin{array}{c}\text { Direktor } \\
\text { 15 (D1) }\end{array}$ & 3.61 \\
\hline
\end{tabular}

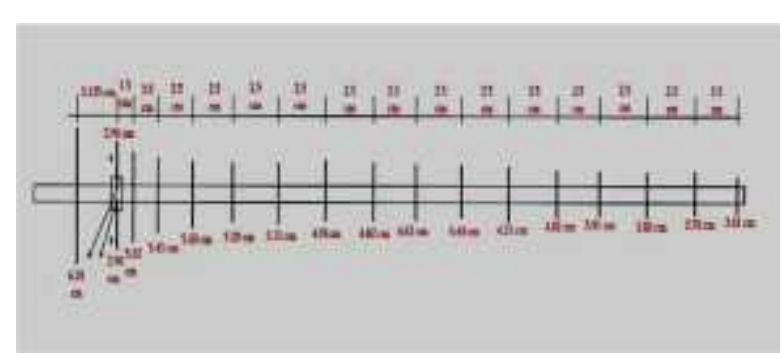

Gambar 3. Model Perancangan Antena Yagi 15 Elemen

\section{Perakitan Berdasarkan Perhitungan.}

1. Berdasarkan pada rumus perhitungan untuk elemen director yang elemennya lebih pendek dari elemen lain adalah $\mathrm{L}_{\mathrm{d}}=$ $5.640 \mathrm{~cm}$ Langkah selanjutnya diukur menggunakan mistar supaya sesuai ukuran pada rumus perhitungan dan selanjutnya dipotong menggunakan gergaji.

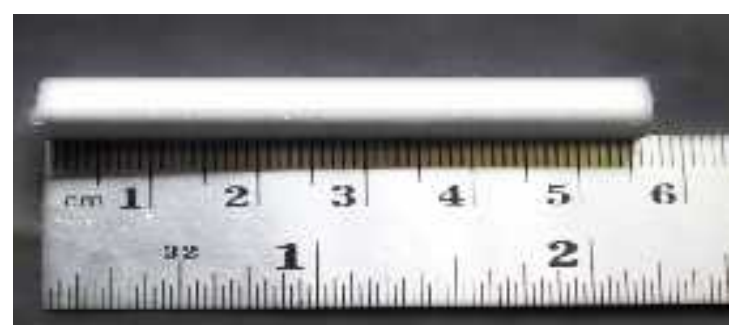

Gambar 4. Elemen Director

2. Sesuai rumus perhitungan untuk elemen reflector yang lebih panjang yaitu $\mathrm{L}_{\mathrm{r}}=$ $6.353 \mathrm{~cm}$

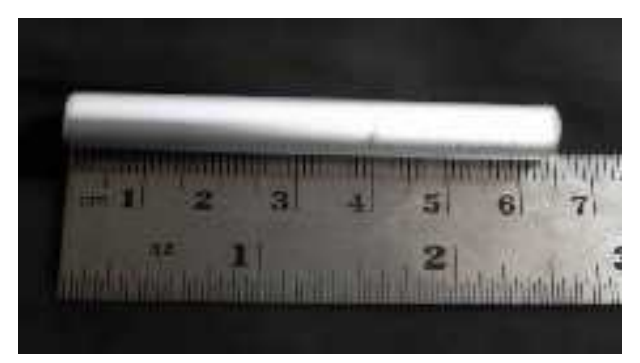

Gambar 5. Elemen Reflector

3. Elemen driven yang dibuat pada rumus perhitungan $\mathrm{L}=5.9375 \mathrm{~cm}$. Tapi disini elemen driven harus dipisahkan dengan ukuran $\mathrm{L} / 2=2.968 \mathrm{~cm}$. Karena dipisahkan maka mempunyai jarak antar kedua elemen driven adalah $\mathrm{a}=0.01 . \lambda=$ $0.125 \mathrm{~cm}=1.25 \mathrm{~mm}$ 


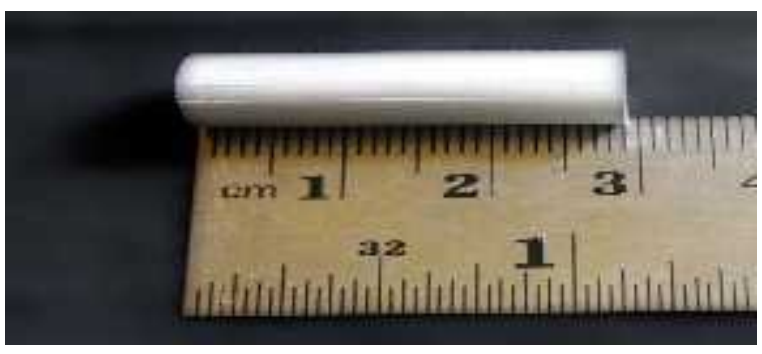

Gambar 6. Elemen Driven yang Dipisahkan

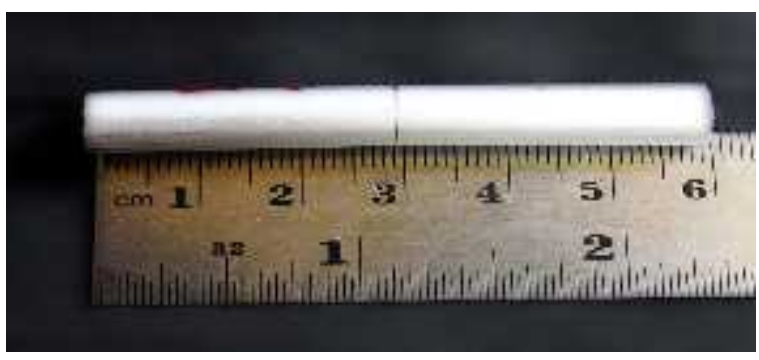

Gambar 7. Panjang Elemen Driven

4. Selanjutnya mempersiapkan boom (almunium), dilubangi dengan bor untuk memasukan elemen pada boom sehingga mempermudah pemasangan elemenelemen yang berjumlah 15 elemen.

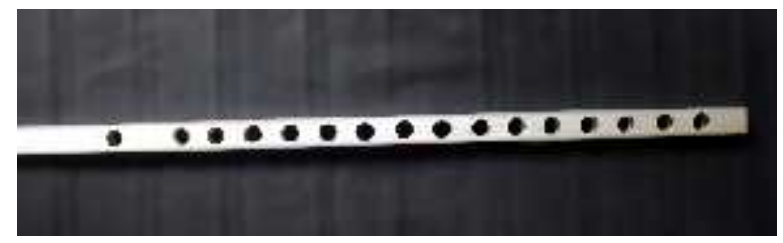

Gambar 8. Boom Antena

5. Memasang elemen pada boom menggunakan ukuran sesuai rumus perhitungan. Jarak antara setiap elemen yang akan dipasangkan pada crossbar $\mathrm{s}=$ $0.2 \lambda=2.5 \mathrm{~cm}$

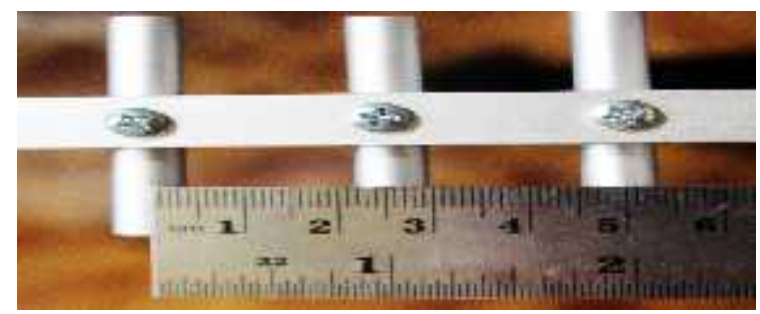

Gambar 9. Jarak Elemen pada Boom
6. Sesudah pemasangan elemen pada boom selesai, selanjutnya membuat brass wire atau antena folded dipolenya untuk disambungkan ke $\mathrm{N}$ konektor. Ini merupakan inti dari pembuatan antena, dengan maksud supaya frekuensi yang diharapkan bisa tercapai.

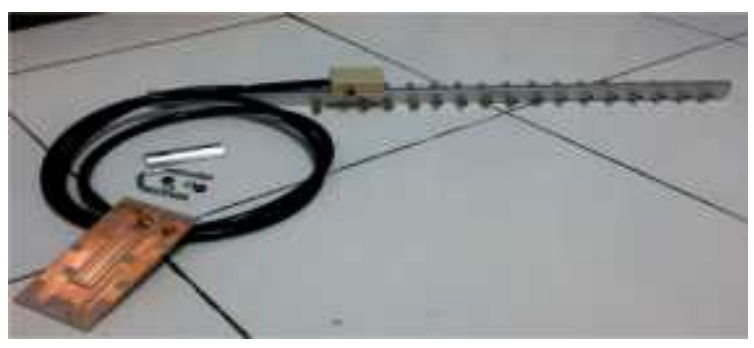

Gambar 10. Antena yagi hasil rancangan

\section{Skala Tingkatan Level Sinyal}

Tabel 2 merupakan skala tingkatan level sinyal hasil kualitatif dari pengamatan.

Tabel 2. Skala Tingkatan Level Sinyal

\begin{tabular}{|c|c|c|}
\hline $\begin{array}{c}\text { Tingkat Kuat } \\
\text { Sinyal (bar } \\
\text { sinyal) }\end{array}$ & Kategori & $\begin{array}{c}\text { Nilai Kuat } \\
\text { Sinyal (dBm) }\end{array}$ \\
\hline 4 & Baik & $-50 \mathrm{~s} / \mathrm{d}-55$ \\
\hline 3 & Cukup & $-55 \mathrm{~s} / \mathrm{d}-70$ \\
\hline 2 & Buruk & $-70 \mathrm{~s} / \mathrm{d}-90$ \\
\hline 1 & Sangat Buruk & $<-90$ \\
\hline
\end{tabular}

\section{A. Pengujian antenna}

Pada gambar 11 berikut ini merupakan rangkain pengujian penguat Sinyal Wifi. 


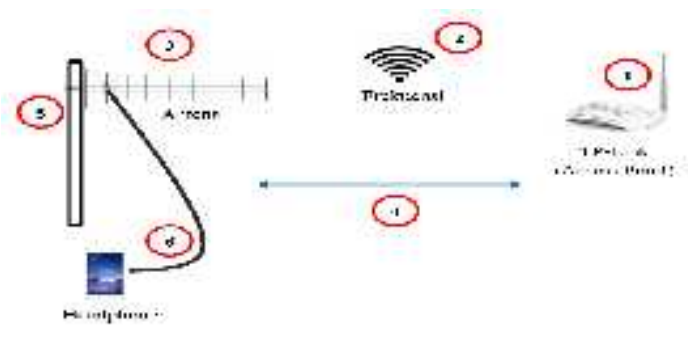

Gambar 11. Rangkaian Pengujian

Keterangan:

1. TP-Link (Acsess Point).

2. Frekuensi yang digunakan $2400 \mathrm{MHz}$

3. Antena Yagi penguat sinyal wifi.

4. Jarak antenna yagi dengan acsess point bervariasi hingga 30 meter.

5. Ketinggian antenna yagi penguat sinyal wifi 1.5 meter dari tanah.

6. Panjang kabel koaksial 2 meter.

Pengujian dilakukan sebelum dan sesudah memakai penguat signal agar dapat diketahui sejauh mana signal itu dikuatkan. Pengujian menggunakan wifi analyzer dengan jarak yang bervariasi hingga jarak 30 meter.

\section{HASIL PENGUJIAN ANTENA}

\section{A. Langkah Pengujian}

Sebelum melakukan pengujian, perlu diperhatikan beberapa hal agar antena dapat bekerja dengan baik.

1. Pengujian dilakukan diluar ruangan. Hal ini bertujuan untuk mendapatkan variasi jarak hingga 30 meter dalam kondisi Los dan Non Los juga untuk kondisi cuaca panas dan hujan.
2. Antena dipasang satu arah lurus kedepan terhadap acsess point dengan ketinggian 1.5 meter dari tanah dan tidak terdapat penghalang.

\section{B. Hasil Pengujian}

Pengujian antenna yagi penguat sinyal wifi diperoleh adanya peningkatnya kuat sinyal wifi yang dibuktikan dengan hasil pengukuran menggunakan wifi analyzer yang dapat menarima koneksi dari acsess point TPLink_CA183A dengan frekuensi 2462 MHz.

\section{Data Hasil Pengujian}

\section{a. Pengukuran untuk kondisi cuaca baik (cerah)}

Pengukuran yang pertama untuk kondisi LOS (Line Of Sight) dari jarak 5 sampai 30 meter. Gambar 12 merupakan hasil pengukuran. Gambar 12 (a) menunjukkan hasil pengukuran sebelum menggunakan antena yagi penguat sinyal. Dapat dilihat nilai kuat sinyal sebesar $57 \mathrm{~dB}$

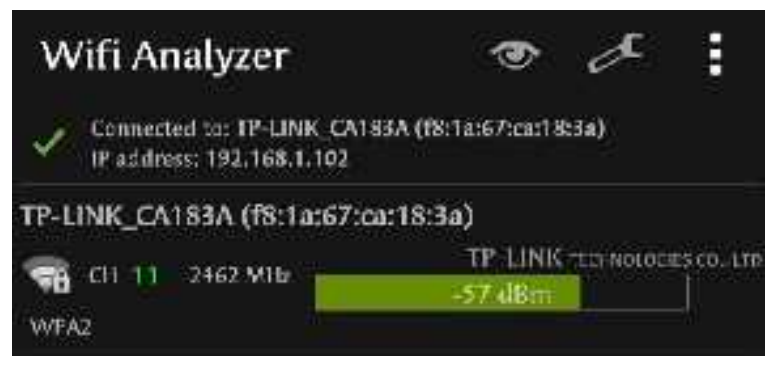

Gambar 12 (a) Pengukuran Antena yagi menggunakan wifi analyzer untuk kondisi Los dengan jarak 5 meter dari acsess point

Gambar 12 (b) menunjukkan hasil pengukuran sesudah menggunakan antena yagi penguat sinyal wifi. Nilai kuat sinyal 
meningkat menjadi $-53 \mathrm{dBm}$, ini berarti terjadi peningkatan nilai kuat sinyal sebesar $4 \mathrm{dBm}$.

Setelah mendapatkan penguatan, antena yagi diuji lagi dengan melakukan browsing dengan menggunakan internet. Hasilnya sangat baik, koneksi tetap stabil dan peningkatan $4 \mathrm{dBm}$ juga menambah kecepatan dalam browsing.

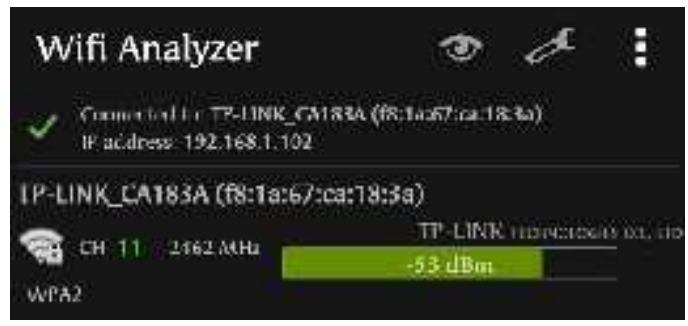

Gambar 12 (b) Pengukuran Antena yagi menggunakan wifi analyzer untuk kondisi Los dengan jarak 5 meter dari acsess point

Pengukuran terus dilakukan sampai 30 meter untuk kondisi LOS (Line of Sight) atau tanpa penghalang. Hasil pengujian antena yagi pada access point, diperoleh peningkatan rata-rata sebesar $3 \mathrm{dBm}$ dari titik pada jarak 5 meter sampai 30 meter.

Pengukuran yang kedua untuk kondisi Non LOS dari jarak 5 sampai 30 meter. Gambar 13 merupakan hasil pengukuran. Gambar 13 (a) menunjukkan hasil pengukuran sebelum menggunakan antena yagi penguat sinyal. Dapat dilihat nilai kuat sinyal sebesar $-66 \mathrm{dBm}$.

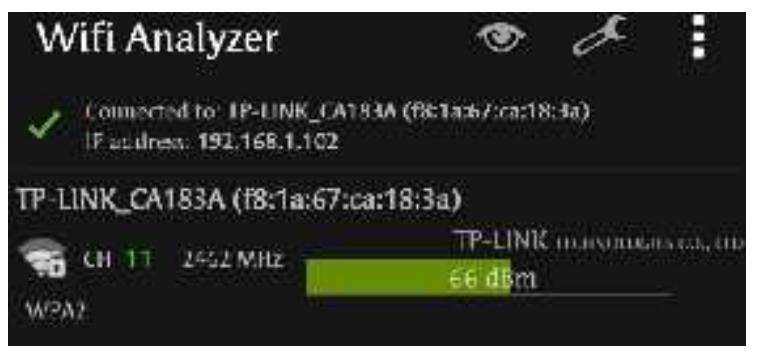

Gambar 13 (a) Pengukuran Antena yagi menggunakan wifi analyzer untuk kondisi Non LOS dengan jarak 5 meter dari acsess point.

Gambar 13 (b) menunjukkan hasil pengukuran sesudah menggunakan antena yagi penguat sinyal wifi. Nilai kuat sinyal meningkat menjadi $-65 \mathrm{dBm}$, ini berarti terjadi peningkatan nilai kuat sinyal hanya sebesar 1dBm. Setelah mendapatkan penguatan, antena yagi diuji lagi dengan melakukan browsing dengan menggunakan internet dan hasilnya cukup baik.

Antena yagi penguat sinyal wifi tidak dapat bekerja dengan baik untuk kondisi Non LOS. Hal ini dapat dilihat dari hasil pengukuran yang hanya meningkatkan sinyal wifi sebesar $1 \mathrm{dBm}$ pada jarak 5 meter dari acsess point dan untuk jarak 10 sampai 30 meter antena yagi wifi tidak dapat digunakan sebagai penguat siyal wifi.

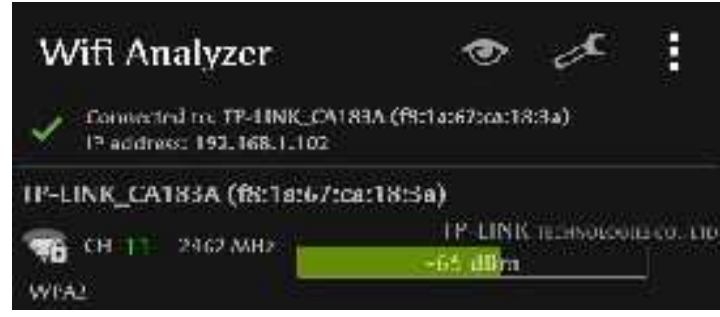

Gambar 13 (b) Pengukuran Antena yagi menggunakan wifi analyzer untuk 
kondisi Non Los dengan jarak 5 meter dari acsess point.

\section{b. Pengukuran untuk kondisi cuaca hujan}

Pengukuran yang pertama untuk kondisi LOS (Line Of Sight) dari jarak 5 sampai 30 meter. Gambar 14 merupakan hasil pengukuran. Gambar 14 (a) menunjukkan hasil pengukuran sebelum menggunakan antena yagi penguat sinyal. Dapat dilihat nilai kuat sinyal sangat buruk diakibatkan kondisi cuaca sedang hujan yaitu $-69 \mathrm{dBm}$ pada jarak 5 meter.

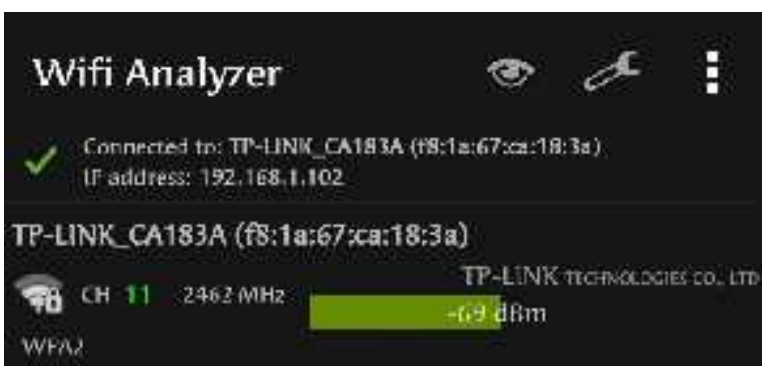

Gambar 14 (a) Pengukuran Antena yagi menggunakan wifi analyzer untuk kondisi Los dan kondisi hujan dengan jarak 5 meter dari acsess point

Gambar 14 (b) menunjukkan hasil pengukuran sesudah menggunakan antena yagi penguat sinyal wifi. Nilai kuat sinyal masih sama yaitu $-69 \mathrm{dBm}$. Setelah dilakukan browsing mengunakan internet juga hasilnya sangat buruk karena kecepatan internet sangat lambat.

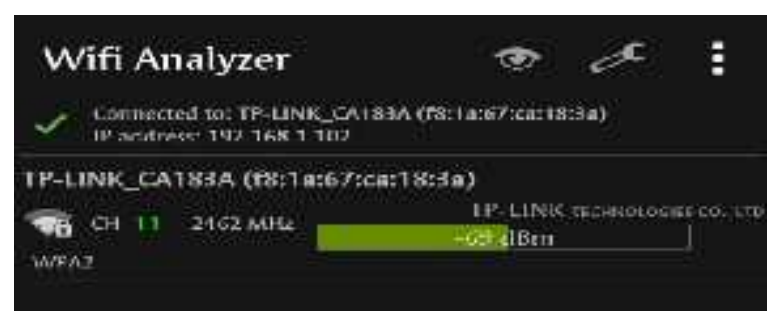

Gambar 14 (b) Pengukuran Antena yagi menggunakan wifi analyzer untuk kondisi Los dan kondisi hujan dengan jarak 5 meter dari acsess point

\section{c. Hasil Pengukuran Antena Yagi Penguat Sinyal Wifi}

Hasil pengukuran antenna yagi penguat sinyal wifi dapat dilihat pada tabel dibawah ini :

Tabel 3 Hasil pengujian kondisi cuaca baik

\begin{tabular}{|c|c|c|c|c|}
\hline \multirow{2}{*}{$\begin{array}{c}\text { Jarak } \\
(\mathbf{m})\end{array}$} & \multicolumn{2}{|c|}{ Tanpa Antena } & \multicolumn{2}{c|}{ Dengan Antena } \\
\cline { 2 - 5 } & $\begin{array}{c}\text { Los } \\
\mathbf{d B m}\end{array}$ & $\begin{array}{c}\text { Non Los } \\
(\mathbf{d B m})\end{array}$ & $\begin{array}{c}\text { Los } \\
(\mathbf{d B m})\end{array}$ & $\begin{array}{c}\text { Non Los } \\
(\mathbf{d B m})\end{array}$ \\
\hline $\mathbf{5}$ & -57 & -66 & -52 & -65 \\
\hline $\mathbf{1 0}$ & -67 & -76 & -64 & -76 \\
\hline $\mathbf{1 5}$ & -78 & -82 & -75 & -82 \\
\hline $\mathbf{2 0}$ & -83 & -88 & -80 & -88 \\
\hline $\mathbf{2 5}$ & -86 & $\begin{array}{c}\text { No } \\
\text { connecti } \\
\text { on }\end{array}$ & -84 & $\begin{array}{c}\text { No } \\
\text { Connecti } \\
\text { on }\end{array}$ \\
\hline $\mathbf{3 0}$ & $\begin{array}{c}\text { No } \\
\text { Conn } \\
\text { ection }\end{array}$ & $\begin{array}{c}\text { No } \\
\text { connecti } \\
\text { on }\end{array}$ & -88 & $\begin{array}{c}\text { No } \\
\text { Connecti } \\
\text { on }\end{array}$ \\
\hline
\end{tabular}




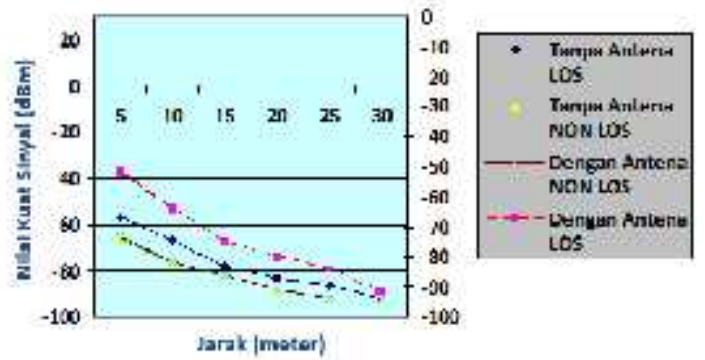

Gambar 15. Grafik Hasil pengujian kondisi cuaca baik

Tabel 3 dapat dilihat bahwa pengujian dilakukan dalam kondisi cuaca yang baik. Pegujian dilakukan hingga jarak 30 meter dan kondisi LOS dan Non LOS. Pengujian tanpa menggunakan antena untuk kondisi LOS koneksi wifi terputus pada jarak 30 meter. Setelah menggunakan antena penguat sinyal wifi meningkat sehingga nilai kuat sinyalnya hanya sebesar $-88 \mathrm{dBm}$ tetapi tidak dapat digunakan untuk mengakses internet.

Pengujian tanpa menggunakan antena untuk kondisi Non LOS koneksi wifi terputus pada jarak 25 meter. Setelah menggunakan antena yagi sebagai penguat, nilai kuat sinyal juga tidak mengalami peningkatan akibat antena dan acsess point terdapat penghalang sehingga antena yagi tidak dapat bekerja dengan baik.

Tabel 4. Hasil pengujian kondisi cuaca hujan

\begin{tabular}{|c|c|c|c|c|}
\hline \multirow{2}{*}{$\begin{array}{c}\text { Jarak } \\
(\text { meter })\end{array}$} & \multicolumn{2}{|c|}{ Tanpa Antena } & \multicolumn{2}{c|}{ Dengan Antena } \\
\cline { 2 - 5 } & $\mathbf{( d B m )}$ & $\begin{array}{c}\text { Non } \\
\text { Los } \\
(\mathbf{d B m})\end{array}$ & $\begin{array}{c}\text { Los } \\
(\mathbf{d B m})\end{array}$ & $\begin{array}{c}\text { Non } \\
\text { Los } \\
(\mathbf{d B m})\end{array}$ \\
\hline $\mathbf{5}$ & -64 & -88 & -64 & -88 \\
\hline $\mathbf{1 0}$ & -82 & $\begin{array}{c}\text { No } \\
\text { connect } \\
\text { ion }\end{array}$ & -82 & $\begin{array}{c}\text { No } \\
\text { connect } \\
\text { ion }\end{array}$ \\
\hline
\end{tabular}

\begin{tabular}{|l|c|c|c|c|}
\hline 15 & No & No & No & No \\
& connect & connect & connect & connect \\
& ion & ion & ion & ion \\
\hline
\end{tabular}

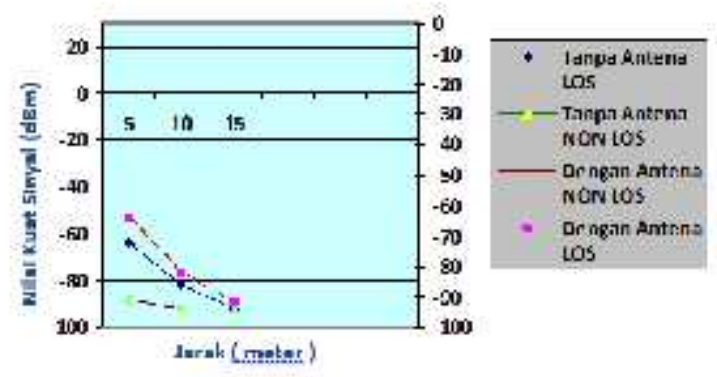

Gambar 16. Grafik Hasil pengujian kondisi cuaca hujan

Tabel 4 dapat dilihat bahwa pengujian dilakukan dalam kondisi cuaca sedang hujan. Pegujian hanya dilakukan hingga jarak 15 meter karena koneksi wifi sangat lemah. Pengujian dalam kondisi hujan, koneksi wifi sangat lemah yaitu hanya $-64 \mathrm{dBm}$ pada jarak 5 meter dan $-82 \mathrm{dBm}$ pada jarak 10 meter kemudian wifi terputus pada jarak 15 meter untuk kondisi LOS. Pengujian dalam kondisi hujan, koneksi wifi sangat lemah dengan nilai kuat sinyal hanya $-64 \mathrm{dBm}$ pada jarak 5 meter dan -82 dBm pada jarak 10 meter kemudian wifi terputus pada jarak 15 meter untuk kondisi LOS. Pada jarak 5 meter koneksi wifi masih dapat digunakan untuk browsing menggunakan internet tetapi kecepatan browsing lambat, sedangkan pada jarak 10 meter kecepatan browsing menggunakan wifi sangat lambat.

Pengujian untuk untuk kondisi Non LOS koneksi wifi semakin lemah. Pada jarak 5 meter nilai kuat sinyal hanya $-88 \mathrm{dBm}$ dan 
MUSTEK ANIM HA Vol. 8 No. 1, April 2019

e-ISSN : 2354-7707 p-ISSN 2089-6697

koneksi wifi terputus pada jarak 10 meter.

Pada jarak 5 meter koneksi wifi sudah tidak dapat digunakan untuk browsing karena koneksi wifi tidak stabil dan sering kehilangan sinyal.

Pengujian saat cuaca sedang hujan koneksi wifi tidak mengalami peningkatan sesudah menggunakan antena yagi sebagai penguat sinyal wifi.

\section{PENUTUP}

\section{Kesimpulan}

1. Perancangan dan perakitan antena yagi penguat sinyal wifi menggunakan bahan alumunium mampu memberikan penguatan sinyal karena bahan alumunium merupakan bahan yang mempunyai sifat konduktivitas panas dan listrik yang baik. Antena yagi penguat sinyal wifi pada frekuensi $2.4 \mathrm{GHz}$, dengan panjang Reflector $6.535 \mathrm{~cm}$, Director $5.62 \mathrm{~cm}$, dan driven yang dipisahkan masing-masing $2.968 \mathrm{~cm}$ dengan ketinggian 1.5 meter dari tanah dapat menguatkan sinyal wifi dengan rata-rata perolehan gain yaitu $3 \mathrm{~dB}$.

2. Antena yagi wifi dapat bekerja dengan baik dengan kondisi LOS dan cuaca yang baik. Kondisi Non LOS menyebabkan antena yagi tidak dapat memancarkan sinyal dengan baik karena terdapat penghalang antara antena dengan acsess point. Kondisi cuaca sangat mempengaruhi kinerja antena yagi penguat wifi karena antena yagi digunakan diluar ruangan.

\section{DAFTAR PUSTAKA}

[1] Balanis, Constantine A. 2005. Antenna Theory - Analisis and Design. Third Edition. New Jersey: John Wiley and Sons.

[2]https://www.academia.edu/13831388/Ana lisis_Quality_Of_Signal_Wifi_Qsw_ Pada_Jaringan_Hotspot_Rt_Rw_Berd asarkan_Jenis_Halangan_Dan_Lokasi

[3] Iqbal, M, 2012. Rancang Bangun Antena Mikrostrip Patch Lingkaran Untuk Memperkuat Sinyal wifi, Medan,Universitas Harapan.

[4] Kraus, John D.2002. Antennas, Third Edition. New York : McGraw-Hill Book Company. Hal: 2, 23, 34

[5] Putra Mandala, 2015. Rancang Bangun Penguat Sinyal GSM Menggunakan Antena Yagi, Tugas Akhir Sarjana, Jurusan Teknik Elektro, Fakultas Teknik, Universitas Musamus, Merauke, Indonesia.

[6] Topalaguna B. dan Ubaid Z. 2012. Konstruksi Prototype Nanosatellite pada Frekuensi ISM Band 2,4 GHz untuk Aplikasi Telemetri Suhu. Tugas Akhir Sarjana, Jurusan Teknik Elektro, Fakultas Teknik, Universitas Hasanuddin, Makassar, Indonesia. 
[7] Utomo, Pramudi. 2008. Teknik Telekomunikasi Jilid 1. Direktorat Pembinaan Sekolah Menengah Kejuruan: Jakarta, Hal 127,

[8] Wowok. 2008. Antena Wireless Untuk Rakyat. Penerbit Andi: Yogyakarta. Hal 14 -16. 21, 79-80 